\title{
AVALIAÇÕES FÍSICO-QUÍMICAS EM FRUTOS DE DIFERENTES GENÓTIPOS DE ACEROLA (MALPIGHIA PUNICIFOLIA L.) ${ }^{1}$
}

\author{
FERNANDO CÉSAR AKIRA URBANO MATSUURA², RICARDO LUÍS CARDOSO ${ }^{3}$, MARÍLIA IEDA DA \\ SILVEIRA FOLEGATTI ${ }^{2}$, JOÃO ROBERTO PEREIRA OLIVEIRA ${ }^{4}$, JORGE ANSELMO BARRETO DE \\ OLIVEIRA $^{5}$, DELFRAN BATISTA DOS SANTOS 5
}

\begin{abstract}
RESUMO - O presente trabalho teve como objetivo avaliar quanto às características químicas e físico-químicas frutos de 12 genótipos de acerola (Malpighia punicifolia L.), em processo de seleção pela Embrapa Mandioca e Fruticultura, visando a identificar aqueles com altos teores de vitamina C e elevada relação Brix/acidez. Os frutos analisados foram colhidos no estágio de maturação "de vez", na safra de setembro a outubro dos anos de 1997 e 1998. Os resultados obtidos para vitamina C variaram de 835 a $1820 \mathrm{mg}$ de ácido ascórbico por $100 \mathrm{~g}$ de polpa, para sólidos solúveis totais de 6,0 a 11,6\%, para acidez total titulável de 0,69 a 1,65\%, para relação Brix/ acidez de 4,24 a 11,59 e para pH de 3,08 a 3,57. Dentre os genótipos analisados, o CMF022 e o CMF019 apresentaram os maiores teores de vitamina $C$ e os menores valores para a relação Brix/acidez, enquanto os genótipos CMF015, CMF008 e CMF010 apresentaram a maior relação Brix/acidez, nos dois anos do experimento.
\end{abstract}

Termos para indexação: cereja-das-Antilhas, vitamina C, relação Brix/acidez, pós-colheita

\section{PHYSICOCHEMICAL EVALUATION IN FRUITS FROM DIFFERENT GENOTYPES OF BARBADOS CHERRY (Malpighia punicifolia L.)}

\begin{abstract}
The objective of this work was to evaluate chemical and physicochemical characteristics of fruits of 12 west indian cherry (Malpighia punicifolia L.) genotypes undergoing a selection process at Embrapa Cassava and Fruit Crops, aiming to identify those with high vitamin C content and total soluble solids (TSS)/total titratable acidity (TTA) ratio. Fruits were harvested at the half mature stage in the September/October harvest, in 1997 and 1998. The results showed values ranging from 835 to $1,820 \mathrm{mg}$ of ascorbic acid per $100 \mathrm{~g}$ of pulp, 6.0 to $11.6 \%$ for the TSS, 0.69 to $1.65 \%$ for the TTA, 4,24 to 11,59 for the TSS/TTA ratio and 3.08 to 3.57 for the pH. Among the genotypes studied, CMF022 and CMF019 presented the highest vitamin C content and the lowest TSS/TTA ratio, whereas CMF015, CMF008 and CMF010 had the highest TSS/TTA ratio, in 1997 and 1998.
\end{abstract}

Index terms: West Indian cherry, vitamin C, post-harvest.

\section{INTRODUÇÃO}

Diversas pesquisas vêm sendo realizadas, nas diferentes áreas componentes do segmento de pós-colheita, visando à descoberta de novas fontes nutricionais e sua utilização, a redução de perdas pós-colheita, o aproveitamento de subprodutos e resíduos da produção agrícola para a alimentação humana e animal e a minimização das perdas nutricionais provocadas pelo processamento de alimentos.

As frutas e vegetais são responsáveis por $95 \%$ das fontes de ácido ascórbico da alimentação humana, sendo este ácido um dos mais importantes nutrientes encontrados nestes alimentos (Henshall, 1981).

A acerola destaca-se como uma fonte nutricional com elevado conteúdo de vitamina $\mathrm{C}$. O teor de ácido ascórbico em acerola tem sido reportado por vários autores. Asenjo \& Guzman (1946) relataram valores entre 1.000 e 3.300 mg de ácido ascórbico por $100 \mathrm{~g}$ de polpa de acerola; Jafle et al. (1950), na Venezuela, encontraram o valor médio de $1.130 \mathrm{mg}$; Cravioto (1951), no México, obteve o valor de $2.520 \mathrm{mg}$; Jackson \& Pennock (1958), em Porto Rico, entre 1.580 e 2.750 mg; Miller et al. (1961), no Havaí, de $2.329 \mathrm{mg}$. No Brasil, Rocha (1988) encontrou teores ao redor de $1.500 \mathrm{mg}$ por $100 \mathrm{~g}$ de polpa. Cavalcante (1991) determinou o teor de vitamina $\mathrm{C}$ em frutos provenientes dos Estados de Pernambuco, Ceará e São Paulo, obtendo os valores médios de $2.808,1.949$ e $1.640 \mathrm{mg}$ de ácido ascórbico por $100 \mathrm{~g}$ de polpa, respectivamente. O mais alto valor de ácido ascórbico reportado na literatura $-4.676 \mathrm{mg}$ de ácido ascórbico por $100 \mathrm{~g}$ de matéria comestível - foi obtido por Mustard (1946), em frutos verdes colhidos na Flórida.

A quantidade de vitamina $\mathrm{C}$ encontrada em acerola apresenta diferenças de acordo com a variedade (aspecto genético), o estágio de maturação do fruto, a época do ano da colheita, os métodos culturais, a fertilidade e disponibilidade de

1 (Trabalho 188/2000). Recebido: 28/08/2000. Aceito para publicação: 23/08/2001.

2 Pesquisador Tecnologia de Alimentos do Laboratório de Ciência e Tecnologia de Alimentos da Embrapa Mandioca e Fruticultura, Caixa Postal 007, CEP 44.380-000, Cruz das Almas, BA.

3 Professor Tecnologia de Alimentos do Departamento de Química Agrícola da Escola de Agronomia da Universidade Federal da Bahia, Caixa Postal 082, CEP 44.380-000, Cruz das Almas, BA.

4 Pesquisador de Fitotecnia da cultura da acerola da Embrapa Mandioca e Fruticultura

5 Estudante de graduação da Escola de Agronomia da Universidade Federal da Bahia 
nutrientes do solo e o clima (temperatura, precipitação pluvial, insolação) do local de cultivo (Nakasone et al., 1966; Henshall, 1981).

Frutos verdes apresentam maior concentração de ácido ascórbico em comparação aos parcialmente (“de vez”) ou completamente maduros (Asenjo, 1946; Mustard, 1946; Asenjo \& Moscoso, 1950; Arostegui et al., 1955; Moscoso, 1956). Itoo et al. (1990) compararam os teores de ácido ascórbico de frutos de aceroleiras cultivadas em três diferentes regiões do Japão, colhidos em três estágios de maturação (com coloração verdeclara-imaturos; vermelho-clara - "de vez" e vermelho-intensamaduros). $\mathrm{O}$ teor de ácido ascórbico dos frutos imaturos foi o mais alto encontrado $-3200 \mathrm{mg} / 100 \mathrm{~g}$ de polpa - diminuindo com o amadurecimento dos frutos. A região de cultivo teve influência na concentração de ácido ascórbico dos frutos.

O Brasil apresenta condições ideais para o cultivo da acerola, sendo um dos maiores produtores mundiais desta fruta, com parte de sua produção comercializada na forma de polpa. Entretanto, essa planta ainda não possui variedades definidas, consistindo em um dos principais fatores que, associado ao plantio de mudas obtidas por via sexuada, levam à grande desuniformidade (quantitativa e qualitativa) da produção brasileira desta fruta.

Couceiro (1986) mencionou trabalhos de melhoramento realizados nas Universidades de Porto Rico, Havaí e Flórida, nos quais foram selecionadas e produzidas variedades e clones com boas características agronômicas (porte da planta, produtividade, tamanho do fruto) e relacionadas à qualidade dos frutos (sabor e conteúdo de vitamina $\mathrm{C}$ ). As variedades que apresentaram teor de ácido ascórbico superior a $1.000 \mathrm{mg}$ por $100 \mathrm{~g}$ de suco foram consideradas satisfatórias. Classificaram-se as variedades em doces e ácidas com base na avaliação sensorial (sabor) dos frutos. Dentro dos grupos ácido e doce, adotou-se como critério de seleção, primeiramente, o teor vitamínico (Nakasone et al., 1968; Arostegui, 1955) e, secundariamente, outras características como porte da planta e produtividade; tamanho e teor de açúcares dos frutos (Alves, 1992). Foram selecionadas as variedades B-17 e B-15 (grupo ácido) na Agricultural Experiment Station University of Porto Rico; a Florida Sweet ou K-7 (grupo doce) na Tropical Experiment Station -University of Florida; a Mamoa Sweet (4-43), Tropical Ruby (9-68), Hawaiian Queen (8E-32) (grupo doce) e J. H. Beaumont (3B-21), C. F. Rehnborg (22-40), F. Haley (3 alb), Red Jumbo (3B-1), Maunawili (8) (grupo ácido) na Hawaii Agricultural Experiment Station - University of Hawaii. Jackson e Pennock (1958) avaliaram a variedade B-15 durante cinco anos e encontraram médias de $2.000 \mathrm{mg}$ de ácido ascórbico por $100 \mathrm{~g}$ de polpa.

No Brasil, existe uma carência de material genético de elite. Há poucas variedades superiores recomendadas e informações disponíveis a este respeito.

A Embrapa Mandioca e Fruticultura apresenta cerca de 150 genótipos de acerola em seu Banco Ativo de Germoplasma, que vêm sendo descritos quanto a características agronômicas e físico-químicas dos frutos, por meio de análises de $\mathrm{pH}$, acidez, sólidos solúveis totais e vitamina $\mathrm{C}$.

O presente trabalho teve como objetivo avaliar aspectos químicos e físico-químicos dos frutos de doze genótipos de acerola em processo de seleção pela Embrapa Mandioca e Fruticultura, visando, principalmente, a identificar aqueles com altos teores de vitamina $\mathrm{C}$ e relação Brix/acidez.

\section{MATERIAIS E MÉTODOS}

No presente estudo, foram utilizados frutos em estágio de maturação "de vez" (frutos vermelhos com porção - 30\% amarelada) colhidos na safra de setembro a outubro dos anos de 1997 e 1998 (estando as plantas com, respectivamente, 45/46 e $57 / 58$ meses de plantio). A colheita foi feita ao acaso e os frutos foram selecionados, eliminando-se os estragados e os que não se encontravam no estágio de maturação adequado. As análises dos frutos foram realizadas imediatamente após a colheita.

Foram utilizados frutos de genótipos de aceroleira do Banco Ativo de Germoplasma da Embrapa Mandioca e Fruticultura (Cruz das Almas, BA), provenientes da cidade de Nova Soure, região noroeste da Bahia, propagados por estaquia. A área na qual foram plantados, tem solo tipo Latossolo Amarelo. A adubação de plantio (na cova) correspondeu a $20 \mathrm{~L}$ de esterco bovino, $300 \mathrm{~g}$ de superfosfato simples, $70 \mathrm{~g}$ de cloreto de potássio e $30 \mathrm{~g}$ de FTE por planta e, após seis meses, procedeu-se à aplicação de $100 \mathrm{~g}$ de uréia (por cobertura). A adubação de manutenção aplicada no ano de 1997 correspondeu a $134 \mathrm{~g}$ de uréia, $134 \mathrm{~g}$ de cloreto de potássio e $800 \mathrm{~g}$ de superfosfato simples; a aplicada em 1998 correspondeu a $260 \mathrm{~g}$ de uréia e $530 \mathrm{~g}$ de cloreto de potássio por planta. O cultivo foi conduzido sem irrigação. O delineamento adotado para o plantio dos genótipos foi o inteiramente casualizado, com cinco repetições por genótipo (uma planta representando uma repetição).

Os frutos foram analisados quanto ao $\mathrm{pH}$ (medida direta em potenciômetro), acidez total titulável (método $\mathrm{n}^{0} 22.038 \mathrm{da}$ A.O.A.C., 1984), sólidos solúveis totais (leitura direta em refratômetro) e ácido ascórbico (método no 43.056 da A.O.A.C., 1984, modificado por Benassi, 1990, que substituiu o solvente extrator ácido metafosfórico por ácido oxálico).

O delineamento experimental utilizado para as análises químicas e físico-químicas dos frutos correspondeu ao inteiramente casualizado, considerando-se 12 genótipos (fator de variação) e três repetições por genótipo. Foram colhidos 30 frutos de cada uma das cinco plantas de cada genótipo, totalizando 150 frutos por genótipo. Deste total, foram retiradas três amostras com 30 frutos cada. As análises estatísticas foram feitas empregando-se análise de variância, seguida de teste Tukey para a comparação de médias.

\section{RESULTADOS E DISCUSSÃO}

Os valores de $\mathrm{pH}$ obtidos foram superiores a 3,0 (3,08 $3,57)$ em todos os genótipos analisados (Tabela 1). Estes valores estão dentro da faixa considerada normal para acerola neste estágio de maturação (“de vez”) e próximos dos valores encontrados por Asenjo \& Moscoso (1950) - entre 3,1 e 3,3. Para esta variável, não houve interação entre os fatores genótipo e ano. Os genótipos CMF019 e CMF018 apresentaram os menores valores para $\mathrm{pH}$, diferindo significativamente dos genótipos CMF016, CMF009, CMF015 e CMF010. Os valores de pH obtidos para os genótipos CMF022 e CMF005 foram significativamente inferiores apenas ao do genótipo CMF010, que apresentou o maior valor para esta variável. O valor médio de $\mathrm{pH}$ obtido em 1997 foi significativamente inferior ao obtido em 1998 (Tabela 1).

A acidez total titulável variou entre 0,69 e 1,65\% (Tabela 
TABELA 1 - Valores obtidos nas análises químicas e físico-químicas em frutos de diferentes genótipos de acerola. Cruz das AlmasBahia, 1997 e 1998.

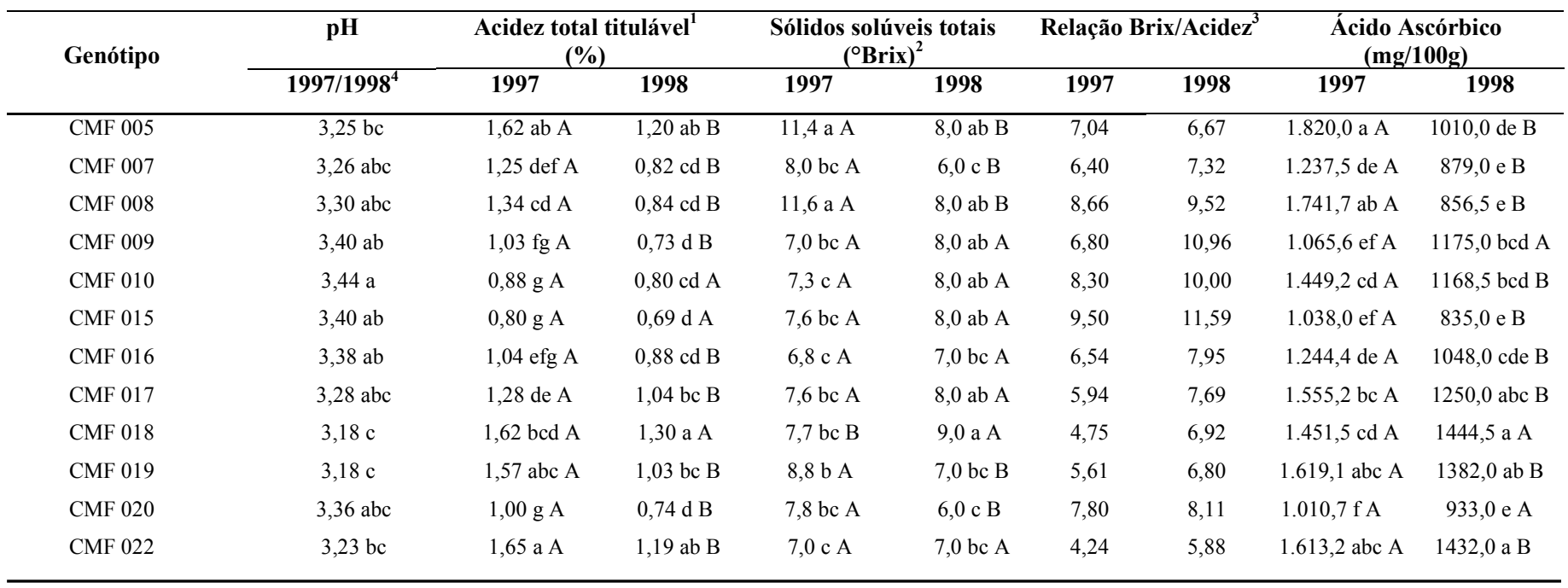

Médias seguidas de mesma letra minúscula, na mesma coluna, não diferem entre si, pelo teste de Tukey a $5 \%$.

Médias seguidas de mesma letra maiúscula, na mesma linha, não diferem entre si, pelo teste de Tukey a $5 \%$.

1: Expresso em ácido málico.

2: Corrigido para a temperatura de $20^{\circ} \mathrm{C}$.

3: Resultado da divisão do valor de sólidos solúveis totais em graus Brix pela porcentagem de acidez total titulável.

4: Média dos anos de 1997 e 1998. Para os dados de pH, não houve interação entre os fatores genótipo e ano.

TABELA 2 - Médias dos dados meteorológicos dos meses de agosto, setembro e outubro e médias anuais de 1997 e 1998.

\begin{tabular}{ccccc}
\hline & \multicolumn{3}{c}{ Média dos meses } & \multicolumn{2}{c}{} \\
Índices & agosto/setembro/outubro & \multicolumn{2}{c}{ Média Anual } \\
& $\mathbf{1 9 9 7}$ & $\mathbf{1 9 9 8}$ & $\mathbf{1 9 9 7}$ & $\mathbf{1 9 9 8}$ \\
\hline Temperatura Média $\left({ }^{\circ} \mathrm{C}\right)$ & 23,1 & 23,1 & 23,9 & 24,7 \\
Precipitação Pluviométrica $(\mathrm{mm})$ & 56,7 & 88,5 & 100,9 & 87,9 \\
Dias de Chuva & 11 & 14 & 14,8 & 14,8 \\
Umidade Relativa (\%) & 78,3 & 82,3 & 80 & 81 \\
Insolação (horas) & 210,1 & 222,1 & 184,6 & 207,7 \\
\hline
\end{tabular}

Fonte: Estação Agrometeorológica da Embrapa Mandioca e Fruticultura.

1). Os genótipos CMF022 e CMF005, que apresentaram valores baixos para $\mathrm{pH}$, obtiveram porcentagens de acidez elevadas nos dois anos do experimento $\left(\mathrm{p}^{3} 0,05\right)$; os genótipos CMF019 e CMF018, que apresentaram os menores valores de $\mathrm{pH}$, obtiveram porcentagens de acidez altas nos anos de 1997 e 1998, respectivamente. A interação entre genótipo e ano foi altamente significativa para esta variável (Tabela 1). Em 1997, o genótipo CMF 022 apresentou a maior porcentagem de acidez, não diferindo significativamente dos genótipos CMF005 e CMF019, enquanto os genótipos CMF015, CMF010 e CMF020 obtiveram os menores valores para acidez, não diferindo significativamente apenas dos genótipos CMF009 e CMF016. Em 1998, os genótipos CMF005 e CMF022, novamente, e o genótipo CMF018 apresentaram valores de acidez superiores aos dos demais genótipos (sendo que os genótipos CMF005 e CMF022 não diferiram significativamente dos CMF017 e CMF019); as menores porcentagens de acidez encontradas foram as dos genótipos CMF015, CMF009 e CMF020 que, porém, não diferiram daquelas encontradas para os genótipos CMF010, CMF007, CMF008 e CMF016. Exceto para os genótipos CMF010 e CMF015, cujos valores não diferiram entre anos, os valores de acidez obtidos para os demais genótipos foram significativamente mais altos em 1997.
Os teores de ácido ascórbico encontrados variaram de 835 a $1.820 \mathrm{mg}$ por $100 \mathrm{~g}$ de polpa. Asenjo \& Moscoso (1950), em trabalho conduzido em Porto Rico, obtiveram valores entre 1.338 e $2.360 \mathrm{mg}$ de ácido ascórbico por $100 \mathrm{~g}$ de polpa para frutos "de vez"; Guadarrama (1984) relatou valores médios de $1.500 \mathrm{mg}$ de ácido ascórbico por $100 \mathrm{~g}$ de polpa. Todos os genótipos, exceto os CMF015, CMF008, CMF007 e CMF020 analisados em 1998, apresentaram teores acima de $1.000 \mathrm{mg}$ de ácido ascórbico por $100 \mathrm{~g}$ de polpa, valores satisfatórios, segundo Couceiro (1986). Os genótipos CMF022 e CMF019 apresentaram teores de ácido ascórbico superiores aos dos demais genótipos nos dois anos do experimento. Em 1997, os genótipos CMF005, CMF008, CMF019 e CMF022 apresentaram os maiores teores de vitamina C, sendo que os genótipos CMF019 e CMF022 não diferiram significativamente dos CMF017, CMF018 e CMF010; em 1998, os genótipos CMF018 e CMF022 apresentaram teores de vitamina $\mathrm{C}$ mais altos que os dos demais, não diferindo significativamente apenas dos genótipos CMF019 e CMF017. Exceto para os genótipos CMF009, CMF018 e CMF020, cujos teores de ácido ascórbico não diferiram entre anos, os valores encontrados em 1997 foram superiores aos de 1998. Este resultado poderia ser explicado pelo baixo índice pluviométrico observado nos meses de agosto a outubro do ano de 1997, em média $56,7 \mathrm{~mm}$, contra $88,5 \mathrm{~mm}$ para o mesmo período em 1998 , e particularmente pelo observado no mês de setembro de 1997, de apenas $9,4 \mathrm{~mm}$, contra 72,3 mm em 1998 (Tabela 2). Segundo Simão (1971), em condições de baixa precipitação pluviométrica, ocorre a formação de frutos com menor teor de umidade e, conseqüentemente, maior concentração dos demais componentes, inclusive açúcares, ácidos orgânicos e ácido ascórbico. Vale ressaltar que os teores de acidez e sólidos solúveis totais também foram maiores para os frutos analisados em 1997. Reforça esta explicação a referência de Moscoso (1956) a uma possível influência da quantidade de água disponível para a planta sobre o teor de ácido ascórbico do 
fruto. Os genótipos que apresentaram os maiores teores de vitamina C, CMF022 e CMF019 em 1997 e 1998, CMF005 em 1997 e CMF018 em 1998, apresentaram também as maiores porcentagens de acidez. Diversos autores (Asenjo \& Guzman, 1946; Moscoso, 1950; Nakasone et al., 1968 e Couceiro, 1986) mencionam o fato de que variedades de acerola mais ácidas apresentam teores mais altos de vitamina $\mathrm{C}$.

Os teores de sólidos solúveis totais obtidos variaram de 6,0 a 11, $6^{\circ}$ Brix. Os genótipos CMF008 e CMF005 apresentaram teores altos de sólidos solúveis totais nos dois anos do experimento, sendo significativamente superiores aos demais genótipos no ano de 1997. O maior teor de sólidos solúveis totais encontrado em 1998 foi o do genótipo CMF018, embora este não tenha diferido significativamente dos teores obtidos para seis outros genótipos (CMF008, CMF009, CMF010, CMF015, CMF017 e CMF015). Não houve influência do fator ano para vários genótipos (CMF009, CMF010, CMF015, CMF016, CMF017 e CMF022) (Tabela 1). Para os genótipos cujos teores de sólidos solúveis totais diferiram significativamente entre anos, os valores obtidos em 1997 foram superiores aos obtidos em 1998, exceto pelo genótipo CMF018.

Os valores encontrados para a relação Brix/acidez variaram de 4,24 a 11,59. Os genótipos CMF022, CMF018 e CMF019 apresentaram os menores valores para a relação Brix/ acidez e os genótipos CMF015, CMF008 e CMF010 apresentaram os maiores valores para este índice nos dois anos do experimento. A relação Brix/acidez indica o grau de equilíbrio entre o teor de açúcares e ácidos orgânicos do fruto (Viégas, 1991) e está diretamente relacionada à sua qualidade quanto ao atributo sabor, sendo, portanto, um importante parâmetro a ser considerado na seleção de "variedades de mesa", isto é, para consumo "in natura" (Couceiro, 1986).

Observou-se, neste trabalho, que os genótipos que apresentaram boa relação Brix/acidez continham, em contrapartida, baixos teores de vitamina $\mathrm{C}$. Isto poderia ser explicado, em parte, pelo fato de haver uma relação direta entre o teor de ácidos totais e o teor de ácido ascórbico em frutos de acerola. Os genótipos cujos frutos apresentam baixos teores de acidez e ácido ascórbico, apresentaram maior relação Brix/acidez para um mesmo teor de sólidos solúveis totais. Esta observação é um indicativo de que, dificilmente, um mesmo genótipo somaria as características de elevada relação Brix/acidez e alto teor de vitamina $C$. Se esta proposição se confirmar verdadeira, a seleção de genótipos deverá ser direcionada para uma ou outra característica: elevada relação Brix/acidez ou alto teor de ácido ascórbico.

\section{CONCLUSÕES}

Considerando-se todas as determinações químicas e físico-químicas realizadas, destacaram-se os genótipos CMF022, CMF019 e CMF017, por apresentarem teores elevados de vitamina $\mathrm{C}$, e os genótipos CMF015, CMF008 e CMF010, por apresentarem boa relação Brix/acidez, nos dois anos do experimento. Os genótipos CMF005 e CMF008, em 1997, e CMF017 e CMF018, em 1998, obtiveram os valores mais altos para vitamina C, e os genótipos CMF020, em 1997, e CMF009, em 1998, os maiores valores para a relação Brix/acidez, merecendo maiores estudos no sentido de se verificar se os elevados valores obtidos em anos isolados se confirmam.

\section{REFERÊNCIAS BIBLIOGRÁFICAS}

ALVES, R. E. Cultura da Acerola. In: DONADIO, L. C. Curso de Fruticultura Tropical. Jaboticabal,SP: UNESP, 1992. 268p.

A.O.A.C. (Association of Official Analytical Chemists). Official methods of analysis. $14 \mathrm{ed}$. Arlington, 1984. 1141p.

AROSTEGUI, F.; ASENJO, C. F.; MUÑIZ, A. I.; ALEMAÑY, L. Studies on the West Indian Cherry, Malpighia punicifolia L.; observations on a promising selection. Proc. Fla. State Hortic. Soc., v.67, p.250-255, 1955.

ASENJO, C. F. Acerola. In: NAGY, S.; SHAW, P. E. Tropical and Subtropical fruits: composition, properties and uses. Westport: AVI, 1980.p. 341-374.

ASENJO, C. F. Riboflavin content of tropical foods. Food Research, v.11, n.2, p.137, 1946.

ASENJO, C. F.; GUZMÁN, S.F. The high ascorbic acid content of the West Indian Cherry. Science, v.103, p.219, 1946.

ASENJO, C. F.; MOSCOSO, C. G. Ascorbic acid content and other characteristics of the West Indian Cherry. Food Research, v.15, p.103-106, 1950.

BENASSI, M. T. Análise do efeito de diferentes parâmetros na estabilidade de vitamina $\mathrm{C}$ em vegetais processados. Campinas,SP: UNICAMP, 1990. 159p. Tese Mestrado.

CAVALCANTE, M.L. Composição de carotenóides e valor de vitamina A em pitanga (Eugenia uniflora) e acerola (Malpighia glabra L). Rio de Janeiro, RJ: Universidade Federal do Rio de Janeiro, 1991. 90p. Tese Mestrado.

COUCEIRO, E. M. Acerola (Malpighia glabra L.): Fabulosa fonte de vitamina $C$ natural. In: REUNIÃO NORDESTINA DE BOTÂNICA, 10, 1986, Natal. Anais... Natal, RN: RNB, 1986.

CRAVIOTO, R.E. Valor nutritivo de alimentos mexicanos. Ciencia, v.40, p.9-17, 1951.

GOERING, H. K.; VAN SOEST, P. J. Forage Fiber Analysis. Agric. Handbook, n. 375, 1970.

GUADARRARA, A. Algunos cambios quimicos durante la maduración de frutos de semeruco (Malpighia punicifolia L.). R. Fac. Agron. Univ. Centr. Venez., v.13, n.1-4, p.11-128, 1984.

HENSHALL, J.D. Ascorbic acid in fruit juices and beverages. In: COUNSELL, J.N.; HORNING, D.H. eds. Vitamin C (Ascorbic Acid). London: Applied Science, 1981.

ITOO, S.; AIBA, M.; ISHIHATA, K. Ascorbic acid content in 
acerola fruit from different production regions and degrees of maturity, and stability during processing. Journal of Japanese Society of Food Science and Technology, v.37, n.9, p.726-729, 1990.

JACKSON, J.C.; PENNOCK, W. Fruit and vitamin C production of five and six years old acerola trees. Journal of Agricultural University of Puerto Rico, v.42, p.196-199, 1958.

JAFFLE, W. G.; BUDOWSKI, P.; GORRA, G. Estudio sobre el contenido del ácido ascórbico (vitamina $\mathrm{C}$ ) en los principales frutos de Venezuela. Arch. Venez. Nutr., v.1, p.83-106, 1950.

LEDIN, R.B. The Barbados or West Indian Cherry. Florida Agric Exp. Sta., 1958, 27p. (Bulletin, 594).

MILLER, C. D.; WENKAM, N. S.; FITTING, K. O. Acerola: Nutritive value and home use. Hawaii Agric. Exp. Sta., 1961 (Circ. $\left.\mathrm{n}^{\circ} 59\right)$.

MOSCOSO, C.G. West Indian Cherries and the production of ascorbic acid. Agricultural Experiment Station Miscellaneous Publication, v.2, n.4, p.1-8, 1950.

MOSCOSO, C.G. West Indian Cherry: Richest known source of natural vitamin C. Economic Botany, v.10, n.3, p.280-290, 1956.

MUNSELL, H. E. Composition of food plants of Central America. III. Guatemala. Food Research, v.15, p. 34-52, 1950.

MUSTARD, M. J. The ascorbic acid content of some Malpighian fruits and jellies. Science, v.104, p. 230-235, 1946.

NAKASONE, N.Y., YAMANTE, G.M.; MIYASHITA, R.K. Selection, evaluation and naming of acerola (Malpighia glabra L.) cultivars. Hawaii Agricultural Experiment Station, v.65, p.119,1968 .

ROCHA, I.C. Suco de Acerola: Efeito da temperatura de pasteurização e armazenamento. Recife: UFPE, 1988. 105p. Tese Mestrado.

SIMÃO, S. Manual de fruticultura. São Paulo: Agronômica Ceres, p.477-485, 1971.

VIÉGAS, F.C.P. A industrialização dos produtos cítricos. In: RODRIGUEZ, O. et al. ed. Citricultura brasileira. 2. ed. Campinas: Fundação Cargill, 1991.p. 898-922. 